\title{
Editorial
}

\section{The continuous pursuit of smart learning}

\author{
Simon K. S. Cheung, Fu Lee Wang \\ The Open University of Hong Kong, Homantin, Kowloon, Hong Kong SAR
}

\section{Lam For Kwok}

City University of Hong Kong, Kowloon, Hong Kong SAR

\begin{abstract}
With an emphasis on learning flexibility, effectiveness, efficiency, engagement, adaptivity and reflectiveness, smart learning embraces a variety of concepts, including but not limited to personalised learning, adaptive learning, intelligent tutoring, open online learning, blended learning, and collaborative learning. As new concepts continue to evolve, the pursuit of smart learning is ongoing, mainly in areas pertaining to the design and implementation frameworks, pedagogical theories and practices, learners' behaviours and learning pattern, learning and assessment strategies and evaluation of learning performance and perception. This editorial gives an overview of smart learning and provides the context on the latest development of smart learning in which the articles in this special issue are located.
\end{abstract}

Keywords: smart learning, flexible learning, adaptive learning, personalised learning, learning environment, learning engagement

\section{Introduction}

Alongside technological advances and their applications penetrating into all aspects of education, there has been a rising need for "smart" technology-enhanced learning environments that are social, interactive, flexible and learner-centred. In this new learning paradigm, learners are guided to become self-directed, self-motivated, and self-learning by actively engaging in both formal and informal learning at their convenience to acquire new competencies of the 21 st century. The diverse learning needs are satisfied with the provision of adaptive support and learning materials which cater for the individual characteristics, learning preferences and the situated online or real-world contexts (Kim et al., 2012).

These smart environments are coined as smart learning environments, which are enriched by digital, context-aware and adaptive applications and devices to facilitate faster and more effective learning, with an emphasis on personalisation and customisation of learning, provision of feedback, support for selfregulation and autonomy of learning, context awareness and connection capabilities (Koper, 2014). In the literature, smart learning environment has been an emerging research topic. Searching using the keywords "smart learning" and "smart learning environment" in Google Scholar yields over 15,000 and over 2,000 results respectively, and the majority were published within the past 5 years (Google, n.d.).

\section{Characterising smart learning environments}

Smart learning environments emphasise learning flexibility, effectiveness, efficiency, engagement, adaptivity, and reflectiveness (Spector, 2014), where both formal and informal learning are integrated (Gros, 2016). Smart learning environments support personalised and customised learning by tracking individuals' learning progression and processes; analysing their personality traits and skills and adapting curriculum, course content, strategy and support to their individual needs (Kwok, 2015; Zou et al., 2021; Zou \& Xie, 2018). Learning analytics can be used within a smart learning environment to help learners understand their own learning process. Providing feedback serves to inform instructors of the individual learners' affect and suggest non-verbal behaviours to enhance instruction efficiency (Chung et al., 2021; Gomede et al., 2021; Wang et al., 2021). In addition, smart learning environments facilitate learner selfregulation to promote autonomous and lifelong learning by allowing learners to have control over their own learning process (Hui et al., 2020; Kwok \& Hui, 2018; T. L. Wong et al., 2020). 
Smart learning environments emphasise interactive content and services rather than independent adoption of smart devices (Noh et al., 2011). A broad range of technologies have been employed to facilitate smart learning, including digital and mobile devices and sensors, alongside intelligent technologies such as cloud computing, learning analytics, artificial intelligence and augmented and virtual realities (Chen et al., 2021). As these technologies started to evolve a decade ago, related studies revealed that mobile devices are widely used by students (Cheung, 2014), and in particular, students use mobile devices rather than desktops to access the Internet (K. Wong et al., 2015). Digital and mobile devices support diverse communication and interactions for effective learning, particularly in a real-time interactive mode (Hwang \& Fu, 2020). Open online learning has been increasingly popular for self-paced learning with the ever-growing open educational resources available for learners (Cheung, 2019). Intelligent systems and technologies capture learner data to help enhance learning effectiveness and improve instruction practice (Chen et al., 2020; Xie et al., 2019).

\section{In pursuit of smart learning}

Through a comprehensive survey, Hwang (2014) identified six areas of research and development related to smart learning environments: (a) development of implementation frameworks of smart learning environments, (b) interpretation and examination of existing pedagogical theories for smart learning environments, (c) learning and assessment strategies for smart learning, (d) innovative applications of learning and training in the new learning mode, (e) learning performance and perception evaluation and (f) learning behaviour and learning pattern analysis. These essentially form a framework for research on smart learning and smart learning environments in the past, present and future, outlining the scope on the latest development of smart learning, which is the focus of this special issue.

\section{Papers in this special issue}

This special issue on smart learning environments aims to report the latest research findings and share good practices on smart learning environments from different perspectives. By the submission deadline in November 2020, a total of 88 submissions had been received. After a rigorous and highly selective review process, 11 articles were finally accepted. Other than the final article presenting an updated literature review on smart learning and discussing the patterns, trends and directions of research and practice, the special issue has been organised into three sections: design and implementation, pedagogical practices and evaluation of smart learning environments.

\section{Design and implementation of smart learning environments}

In the paper titled "Enabling Adaptive, Personalised and Context-Aware Interaction in a Smart Learning Environment: Piloting the iCollab System", Oliveira et al. introduced an iCollab platform which provides students with a choice of contexts that integrate formal and informal learning opportunities to help engage students. There are features that could be implemented in smart learning environments to enable adaptive, context-based and personalised learning. The results of the evaluation of the iCollab platform show a high level of interaction with the platform, especially social interaction, indicating an interweaving of formal learning in informal spaces. These illustrate how smart learning environments could be designed in ways that combine formal and informal learning contexts to promote student engagement.

The next paper, titled "An Adaptive Learning Module for a Conversational Agent to Support MOOC Learners", González-Castro et al. proposed an adaptive learning module for a conversational agent that complements a massive open online course (MOOC). The module adapts the difficulty of questions provided to learners, considering their level of knowledge using item response theory and recommends relevant video fragments of the MOOC if the learner fails the questions. Evaluation was conducted on the usability, learnability and learning effectiveness, with the aim of illustrating whether a conversational agent adapting questions provided to learners using item response theory could be helpful for learners to review learnt concepts and for instructors to review course contents. 


\section{Pedagogy for smart learning environments}

The paper titled "Evaluating Student Engagement and Deep Learning in Interactive Online Psychology Learning Activities" proposed a mixed-methods design to explore students' interactions with online activities. Sugden et al. investigated how, where and which devices the students used in a series of online activities to evaluate the levels of learning engagement and deep learning with the activities. The study revealed that students used a combination of mobile devices to access the online activities across different locations during opportunistic study sessions. It also revealed that the online activities were perceived positively, facilitating affective, cognitive and behavioural engagement and that authentic tasks with reallife applications were perceived as most beneficial to learning.

The next paper, titled "Students' Motivation Types in the Smart Approach to ESP Instruction" (Simonova et al.), reported the application of a smart approach in teaching two topics in English for specific purposes with regard to four students' motivation types, namely "accurators", "coordinators", "directors" and "explorers". The smart approach includes the exploitation of smart devices and technologies in face-to-face instruction and in-home preparation for lessons. An experiment was set out to investigate if the smart approach can be applied to learners of different motivation types. The results showed that the smart approach suited students of all the four motivation types. In particular, the increase in knowledge for coordinators was significantly higher than that for explorers and directors.

In the paper titled "Sentiment Evolution with Interaction Levels in Blended Learning Environments: Using Learning Analytics and Epistemic Network Analysis", Huang et al. conducted an analysis on sentiment evolution at different interaction levels from the longitudinal data of five learning stages of postgraduate students in a blended learning course. Text mining techniques and epistemic network analysis were employed. The findings showed that student sentiments might change from negative to insightful ones for deep interactions, and that the sentiment network built from social-emotion interactions shows stronger connections in joking-positive and joking-negative sentiments. Their sentiments evolved from positive to confused/negative and then to insightful during the knowledge constructions in blended learning.

The paper titled "Smart Classroom Environments Affect Teacher-Student Interaction: Evidence from Behavioural Sequence Analysis" (Zhan et al.) investigated the effect of classroom settings on teacherstudent interaction by comparing the behavioural sequences in smart classrooms and traditional multimedia classrooms. The results showed that, as compared to traditional multimedia classrooms, smart classrooms triggered significantly more self-initiated student actions and student-driven teacher talk while teacherinitiated talk decreased significantly. These findings suggest that students' autonomy was strengthened in the smart classroom. They help validate the effect of smart classrooms on increasing teacher-student interaction and strengthening the students' dominant position.

\section{Evaluation of smart learning environments}

The paper titled 'Using Automatic Speech Recognition Technology to Enhance EFL Learners' Oral Language Complexity in a Flipped Classroom" (Jiang et al.) presented a study to examine the effects of using automatic speech recognition technology on oral complexity in a flipped English as a Foreign Language course. In a quasi-experiment, the experimental group and the control group were taught with a flipped approach, but the experimental group needed to undertake an additional pre-class task with automatic speech recognition technology. The results showed the experimental group performed better than the control group on lexical complexity and syntactic complexity, while improvement in phrasal complexity was found in both groups. These demonstrated improvement of performance in a smart learning environment.

The next paper, titled "On the Use of Flipped Classroom across Various Disciplines: Insights from a Second-Order Meta-Analysis" (Hew et al.), attempted to synthesise all relevant meta-analytic information and apply a second-order meta-analysis on learning outcomes. A study was conducted to synthesise and analyse the quality of 15 primary meta-analyses that involved 156,722 participants in flipped and nonflipped conditions to provide the most exhaustive test of flipped classroom on its effect on learning outcomes. The accuracy of the second-order meta-analysis results were verified. The findings provided insights planning empirical studies and meta-analysis involving the flipped classroom approach. 
In the paper titled "Digital Game-Based Learning of Information Literacy: Effects of Gameplay Modes on University Students' Learning Performance, Motivation, Self-Efficacy and Flow Experiences”, Zou et al. developed a digital role-playing game to enhance students' learning of information literacy and investigated the effects of gameplay modes on learning performance, motivation, self-efficacy and flow experiences. Based on an experiment in which 90 students played the game in solo, collaborative and competitive modes, it was revealed that the solo mode was inferior to the other two modes, and that the collaborative mode was superior in learning performance and flow experience while the competitive mode was significantly better in terms of promoting self-efficacy.

The next paper, "Employability: Smart Learning in Extracurricular Activities for Developing Graduates' Competencies" (Hui et al.), shifted the focus to extracurricular activities. It reported the development of a central repository on student development activities, which aims to provide a smart way for activity organisers, advisors and students to plan for extracurricular activities. The data on the development activities collected from the system, the data on placement employers' feedback and the data on academic performance for students in computer science were analysed. The results showed that the students' participation level had a positive and significant relationship with their academic performance and that the competency developed by most students had a positive relationship with job performance in the placement.

\section{A review of smart learning environments}

In the final paper, "Review of Smart Learning: Patterns and Trends in Research and Practice", Li and Wong presented an updated review of the literature on smart learning. A total of 90 studies from 2010 to 2019 were analysed for the patterns and trends in terms of publication years, sources of publication, research purposes, research methods, educational levels, application domains, research issues, research participants, learning devices or tools, learning environments and learning features. It was revealed that increasing global attention was given to smart learning from diverse disciplines and contexts of application. The authors identified a number of areas to be addressed in the future work on smart learning, which provide a useful reference for researchers in the field.

\section{Concluding remarks}

Embracing a variety of concepts, including personalised learning, flexible learning, intelligent tutoring, adaptive learning, blended learning, collaborative learning and open online learning, there is obviously no single form of smart learning environments. As new concepts, approaches, methods and technologies continue to evolve, there are always new opportunities for advancing the learning environments in both pedagogical and technological aspects. In other words, the pursuit of smart learning could continue well into the future.

In alignment with the surveys and reviews on smart learning and smart learning environments reported in the literature (Chen et al., 2021; Hwang, 2014) as well as the most recent one by Li and Wong in this special issue, it is clear that future directions for research and development on smart learning environments are in several areas, including but not limited to, the design, development and implementation, pedagogical theories and concepts, learners' behaviours and learning patterns, learning and assessment strategies and evaluation of learning performance and perception. Following these directions, the articles report some of the latest research findings on smart learning environments, pertaining to design and implementation, pedagogical practices, learners' behavioural analysis and evaluation. We hope that you will find them useful.

\section{Acknowledgements}

We would like to express our heartfelt thanks to the AJET editorial team and copyrighters for their support in bringing this special issue to fruition. Thanks also go to the anonymous reviewers for their efforts in the review process. 


\section{References}

Chen, X., Zu, D., Xie, H., \& Wang, F. L. (2021). Past, present, and future of smart learning: A topicbased bibliometric analysis. International Journal of Educational Technology in Higher Education, 18(1), 1-29. https://doi.org/10.1186/s41239-020-00239-6

Chen, X., Xie, H., \& Hwang, G. J. (2020). A multi-perspective study on artificial intelligence in education: Grants, conferences, journals, software tools, institutions, and researchers. Computers and Education: Artificial Intelligence, 1, Article 100005. https://doi.org/10.1016/j.caeai.2020.100005

Cheung, S. K. S. (2014). A survey on the use of mobile devices for learning purposes. International Journal of Innovation and Learning, 16(2), 192-202. https://doi.org/10.1504/IJIL.2014.064366

Cheung, S. K. S. (2019). A study on the university students' use of open educational resources for learning purposes. In S. Cheung, J. Jiao, L. K. Lee, X. Zhang, K. Li, \& Z. Zhan (Eds.), Communications in computer and information science: Vol. 1048. Technology in education: Pedagogical innovations (pp. 146-155). Springer. https://doi.org/10.1007/978-981-13-9895-7_13

Chung, J. W. Y., So, H. C. F., Choi, M. M. T, Yan, V. C. M., \& Wong, T. K. S. (2021). Artificial intelligence in education: Using heart rate variability (HRV) as a biomarker to assess emotions objectively. Computers and Education: Artificial Intelligence, 2, Article 100011. https://doi.org/10.1016/j.caeai.2021.100011

Gomede, E., de Barros, R. M., \& de Souza Mendes, L. (2021). Deep auto encoders to adaptive e-learning recommender system. Computers and Education: Artificial Intelligence, 2, Article 100009. https://doi.org/10.1016/j.caeai.2021.100009

Google. (n.d.). Google Scholar. Retrieved April 30, 2021, from https://scholar.google.com

Gros, B. (2016). The design of smart educational environments. Smart Learning Environments, 3, Article 15. https://doi.org/10.1186/s40561-016-0039-X

Hui, Y. K., Kwok, L. F., \& Ip, H. H. S. (2020). CRESDA: Towards a personalized student advisory for professional development. Interactive Learning Environments, 29(2), 329-342. https://doi.org/10.1080/10494820.2020.1780270

Hwang, G. J., \& Fu, Q. K. (2020). Advancement and research trends of smart learning environments in the mobile era. International Journal of Mobile Learning and Organisation, 14(1), 114-129. https://doi.org/10.1504/IJMLO.2020.103911

Hwang, G. J. (2014). Definition, framework and research issues of smart learning environments: A context-aware ubiquitous learning perspective. Smart Learning Environments, 1, Article 4. https://doi.org/10.1186/s40561-014-0004-5

Kim, T., Cho, J. Y., \& Lee, B. G. (2012). Evolution to smart learning in public education: A case study of Korean public education. In T. Ley, M. Ruohonen, M. Laanpere, \& A. Tatnall (Eds.), Advances in information and communication technology: Vol 395. Open and social technologies for networked learning (pp. 170-178). Springer. https://doi.org/10.1007/978-3-642-37285-8_18

Koper, R. (2014). Conditions for Effective Smart Learning Environments. Smart Learning Environments, 1, Article 5. https://doi.org/10.1186/s40561-014-0005-4

Kwok, L. F. (2015). A vision for the development of i-Campus. Smart Learning Environments, 2, Article 2. https://doi.org/10.1186/s40561-015-0009-8

Kwok, L. F., \& Hui, Y. K. (2018). The role of e-portfolio for smart life long learning. In V. Uskov, J. Bakken, R. Howlett, \& L. Jain (Eds.), Smart innovation, systems and technologies: Vol. 70. Smart universities (pp. 327-356). Springer. https://doi.org/10.1007/978-3-319-59454-5_11

Noh, K. S., Ju, S. H., \& Jung, J. T. (2011). An exploratory study on concept and realization conditions of smart learning. Journal of Digital Convergence, 9(2), 79-88. https://doi.org/10.14400/JDPM.2011.9.2.079

Spector, J. M. (2014). Conceptualizing the emerging field of smart learning environments. Smart Learning Environments, 1, Article 2. https://doi.org/10.1186/s40561-014-0002-7

Wang, J., Xie, H., Wang, F. L., Lee, L.-K., \& Au, O. T. S. (2021). Top-N personalized recommendation with graph neural networks in MOOCs. Computers and Education: Artificial Intelligence, 2, Article 100010. https://doi.org/10.1016/j.caeai.2021.100010

Wong, K., Wang, F. L., Ng, K. K., \& Kwan, R. (2015). Investigating acceptance towards mobile learning in higher education students. Communications in computer and information science: Vol. 494. Technology in education: Transforming educational practices with technology (pp. 9-19). Springer. https://doi.org/10.1007/978-3-662-46158-7_2 
Wong, T.-L., Xie, H., Wang, F. L., Tang, J. K. T., Kong, A., \& Kwan, R. (2020). How to facilitate selfregulated learning? A case study on open educational resources. Journal of Computers in Education, 7, 51-77. https://doi.org/10.1007/s40692-019-00138-4

Xie, H., Zou, D., Zhang, R., Wang, M., \& Kwan, R. (2019). Personalized word learning for university students: A profile-based method for e-learning systems. Journal of Computing in Higher Education, 31(2), 273-289. https://doi.org/10.1007/s12528-019-09215-0

Zou, D., Wang, M., Xie, H., Cheng, G., Wang, F. L., \& Lee, L.-K. (2021). A comparative study on linguistic theories for modeling EFL learners: Facilitating personalized vocabulary learning via task recommendations. Interactive Learning Environments, 29(2), 270-282. https://doi.org/10.1080/10494820.2020.1789178

Zou, D., \& Xie, H. (2018). Personalized word-learning based on technique feature analysis and learning analytics. Journal of Educational Technology and Society, 21(2), 233-244. https://drive.google.com/open?id=1GBwnHKJ5jmRFQ0GrygvEYekr4HrfnZ8H

Corresponding author: Simon K. S. Cheung, kscheung@ ouhk.edu.hk

Copyright: Articles published in the Australasian Journal of Educational Technology (AJET) are available under Creative Commons Attribution Non-Commercial No Derivatives Licence (CC BY-NC-ND 4.0). Authors retain copyright in their work and grant AJET right of first publication under CC BY-NC-ND 4.0 .

Please cite as: Cheung, S. K. S., Wang, F. L., \& Kwok, L. F. (2021). The continuous pursuit of smart learning [Editorial]. Australasian Journal of Educational Technology, 37(2), 1-6.

https://doi.org/10.14742/ajet.7207 